\title{
Entre A Magia e o Pensamento Secular: Reflexões Sobre a Cultura Política Brasileira a Partir das Religiões Populares
}

\author{
RODRIGO LEISTNER ${ }^{1}$
}

\begin{abstract}
Resumo
Numa reflexão de caráter ensaístico, o trabalho examina as interfaces entre os campos religioso e político no Brasil, buscando identificar as possíveis relações entre determinados sistemas de crença e a cultura política brasileira. Questiona-se o modo como as práticas religiosas populares influenciam as pautas de comportamento coletivo e de orientação da ação política de determinados segmentos sociais do país. Para tanto, a discussão concentra-se nas religiões afro-brasileiras e em denominações do campo neopentecostal, que apesar das inúmeras diferenças rituais e cosmológicas, compartilham conteúdos simbólicos comuns, especialmente aqueles associados às concepções mais estabilizadas sobre as "religiosidades populares". Trata-se de avaliar as possíveis influências que os códigos de crença estruturados nessas práticas articulariam junto às atitudes e comportamentos dos adeptos em torno de uma práxis política.
\end{abstract}

Palavras-chave: Religiões populares. Sistemas de crença. Pensamento secular. Cultura política.

1 Doutor em Ciências Sociais pela Universidade do Vale do Rio dos Sinos (UNISINOS) e professor adjunto do Instituto de Ciências Humanas e da Informação (ICHI) - Área de Sociologia, na Universidade Federal do Rio Grande (FURG/RS), Brasil. rodrigoless@yahoo. com.br 


\title{
Between Magical and Secular Thinking: Reflections on Brazilian Political Culture and Popular Religions
}

\begin{abstract}
In a reflection of essayistic character, the article examines the interfaces between religious and political fields in Brazil, seeking to identify possible connections between certain belief systems and Brazilian political culture. We question how popular religious practices could influence the patterns of collective behavior and orientation of the political action by certain social segments of the country. To this end, the discussion focuses on afro-brazilian religions and denominations of neopentecostal religious field. Despite numerous differences present in rituals and cosmological beliefs of both religions systems, they share common symbolic contents, especially those associated with the conceptions more established of "popular religiosity". We intend to evaluate the possible influences that some codes of belief, structured along those practices, articulate on the attitudes and behaviors of followers in the realm of political praxis.
\end{abstract}

Keywords: Popular religions. Belief systems. Secular thought. Political culture.

\section{Notas Introdutórias}

No contexto brasileiro, não são raros os estudos sobre as relações entre religião e política, seja em seus aspectos mais extensos - no que se relaciona com a influência das ideias religiosas sobre o sistema político (PIERUCCI; PRANDI, 1996), seja em suas dimensões mais específicas - no que se refere às micropolíticas endógenas do campo religioso (BRANDÃO, 1986). Como propõe Paula Montero (1999), ressalvando-se a multiplicidade dessas análises e os diferentes recortes disciplinares, é possível verificar que coube à sociologia aquelas iniciativas de uma compreensão mais ampla acerca das interferências entre o religioso e o político, observando-se não apenas a incidência das crenças religiosas sobre os comportamentos eleitorais, mas ainda sua influência sobre a cultura política do país de um modo geral. Aqui, compreende-se não apenas os estudos sobre a Igreja e o catolicismo popular desenvolvidos desde os anos 1980, cujas preocupações orientavam-se a questionar o potencial 
conservador ou progressista daquelas crenças na configuração das mobilizações sociais no país (MAINWARING, 2004), mas também das investigações sobre o pentecostalismo crescente a partir das décadas de 1980 e 1990, que ora o compreenderam como sinônimo de regressão da racionalidade da esfera pública brasileira, ora como possibilidade de empoderamento de atores periféricos (cf. MARIZ, 1991; ROLIM, 1985). Em menor número, mas também importantes, demonstram-se os estudos sobre os vínculos entre as religiões afrobrasileiras e o campo político partidário, cuja tônica, ao menos até os anos 1980, esteve direcionada às reflexões sobre as possibilidades de cooptação de atores afro-religiosos por candidaturas laicas (NEGRÃO; CONCONE, 1985).

É necessário avaliar que tais análises contribuíram para compor um importante conjunto de interpretações sobre a realidade cultural e política brasileira. Concebendo-se a incidência das ideias religiosas sobre os comportamentos políticos como efetiva, e percebendo-se que o país comportava um extenso repertório de práticas e sistemas de representação de ordem popular religiosa (cf. MAGGIE, 1992; MALUF, 2003), diferentes nuances do catolicismo, do pentecostalismo e das religiosidades afro-brasileiras constituíram-se como chaves interpretativas fundamentais para percepções acerca de uma práxis política nacional. Contudo, ao propor análises mais amplas sobre essas realidades, tais estudos incorreram em duas problemáticas (cf. MONTERO, 1999): (I) o foco na dimensão estrutural dos sistemas culturais, sejam eles os sistemas religiosos ou a própria noção de cultura política; (II) o recurso analítico baseado nas categorias da sociologia da religião clássica, sobretudo com a utilização do instrumental de Durkheim e Weber.

Nesse sentido, por um lado, pouca atenção foi dada aos aspectos situacionais e às dimensões da experiência social concreta dos atores envolvidos, nos termos de suas próprias percepções acerca das vinculações ente religião e política. Por outra via, as dicotomias advindas da relação religião versus magia, presentes na sociologia 
clássica, contribuíram para uma categorização etnocêntrica dos sistemas de crença analisados, projetando-se a religiosidade popular como tipificação dos sistemas cognitivos baseados no "pensamento mágico", e por conseguinte, carregados daqueles conteúdos supostamente incompatíveis com a racionalidade política moderna: a ausência de responsabilidade moral, o individualismo exacerbado, a irracionalidade dos sistemas cognitivos.

Em um contexto em que os referenciais teóricos percebiam a modernidade como avanço das perspectivas racionais que ultrapassariam o pensamento mágico/religioso no processo de secularização (condição tida como central para a concretização dos ideais da democracia e cidadania moderna), boa parte dos estudos que arriscaram interpretações sobre as relações entre política e religiões populares no Brasil não vacilaram em projetar as realidades observadas como modelos distantes do padrão cultural e político preponderante nas democracias ocidentais - especialmente pela suposta "contaminação" da esfera pública brasileira pela profusão das crenças "mágicas". Na maioria dos casos, essa discussão esteve baseada em termos opostos como arcaísmo e modernidade, em dualidades discursivas que se ligam ora a imprecisões sobre as possibilidades políticas orientadas por uma perspectiva democrática universalista, ora a constatações sobre uma suposta crise da modernidade política e secular brasileira (PRANDI, 1996). Nesse viés analítico convencional, poucas bases reflexivas foram disponibilizadas para uma compreensão mais acurada das relações entre política e religiões populares no

2 Enquanto Durkheim (1993) observa a religião como um sistema de representações coletivas através das quais os indivíduos compreendem a sociedade da qual são membros, sendo coesão e solidariedade elementos centrais do código religioso (diametralmente oposto às práticas mágicas individualizadas), Weber (1994) busca a identificação dos valores articulados num dado sistema de crenças e dos sentidos da ação religiosa, assim possibilitando a distinção analítica entre as diversas modalidades de crença (novamente religião e magia distanciam-se mediante o sentido moral atribuído à religião e as acepções coercitivas da magia). Em ambas as interpretações, magia e religião constituem um par oposto e apartado por categorias antagônicas como amoralidade e moral comunitária, misticismo e representações coletivas, ação coercitiva e ação reverencial. 
Brasil ${ }^{3}$, em suas lógicas próprias, relativizando-se o tom etnocêntrico das interpretações elaboradas.

Ainda em acordo com Paula Montero (1999), foi somente com base no crescimento dos estudos sobre o campo evangélico a partir dos anos 1990, bem como a partir do processo de redemocratização do país, que novas matrizes interpretativas foram desenvolvidas, através de análises que não se limitaram a constatar as propaladas excentricidades lógicas contidas na relação entre religião e política. Nesses casos, não se tratava mais de perceber as conexões entre o pensamento mágico disseminado entre as camadas populares e as contradições do sistema político brasileiro, mas de analisar um modelo próprio de conciliação entre imaginários políticos e religiosos, que seria característico da modernidade e da esfera pública local, agora compreendida em seus próprios termos. Nesse novo padrão de estudos, observa-se uma profícua diversidade de objetos investigativos através dos quais a relação entre a política e as religiões populares tem sido refletida. Como exemplos específicos do campo pentecostal encontram-se os estudos sobre a formação da "bancada evangélica" (BOHN, 2004; ORO, 2003), a tramitação de projetos legislativos "controversos" promovidos por parlamentares pentecostais (GOMES; NATIVIDADE; MENEZES, 2009) ou ainda os conflitos discursivos estabelecidos entre esses coletivos e os movimentos ligados às agendas da desigualdade de gênero e diversidade sexual (MACHADO, 2015, 2012). Por sua vez, as próprias religiosidades afro-brasileiras receberam maior atenção no que se refere a suas vinculações com a política, caso das análises

3 As exceções a este debate encontram-se nos estudos sobre as Comunidades Eclesiais de Base, que vislumbraram compatibilidades entre crenças populares e uma práxis política libertária (cf. CAMARGO; SOUZA; PIERUCCI, 1983). Contudo, nesse caso trata-se de uma observação sobre a relação entre determinados coletivos e ações políticas organizadas por intelectuais da teologia da libertação, em movimentos cujas bases cognitivas apresentavam uma espécie de mediação que os distanciava dos aspectos percebidos como próprios da religiosidade popular - o caráter mágico que permeia o sistema de crenças. Aqui, a relativização das supostas incompatibilidades entre político e religioso só foi efetiva na medida em que esse mesmo religioso esteve submetido à mediação intelectual que reordenou as bases de um pensamento racionalizado. 
sobre a participação de seus adeptos nos pleitos (DE BEM; LEISTNER, 2010; ORO, 2001), a ação política inspirada por identidades afroreferenciadas (ANJOS, 2006) ou as estratégias de seus membros na ocupação de espaços na esfera pública (CORDOVIL, 2014; LEISTNER, 2011).

Decerto, em que pese o mérito desses estudos, destaquese que a relativização do tom etnocêntrico até então endereçado às percepções sobre a relação da política com as religiosidades populares só foi alcançada a partir de um afastamento das discussões em relação aos questionamentos mais gerais sobre a incidência dos fenômenos religiosos sobre a cultura política nacional, privilegiando-se as análises situacionais. Nesse sentido, esses novos estudos encontram-se muito mais voltados aos aspectos estratégicos e recursivos empregados por atores religiosos na negociação de sua presença na esfera pública do que a interpretações sobre o modo como determinados sistemas cognitivos (religiosos) inspiram uma práxis política. Contudo, considerando-se a amplitude das religiões populares no Brasil, bem como a potencial incidência de seus valores sobre os fenômenos políticos de ampla dimensão, pareceria demasiadamente problemática a revogação das iniciativas de compreensão dos aspectos mais gerais da cultura política brasileira pela "fresta" das religiosidades populares.

É justamente com intuito de retomar essa discussão que este trabalho se desenvolve. Assim, busca-se aqui reorganizar as reflexões sobre a influência das religiões populares na cultura política do país, avaliando o modo como determinados sistemas cognitivos incidem sobre as pautas de orientação política dos atores sociais, considerando, no entanto, a necessidade de evitar certos "deslizes" analíticos que historicamente estiveram presentes neste viés investigativo. Compreendendo-se que o Brasil comporta um amplo sistema de representações baseado naquelas perspectivas geralmente concebidas como "mágicas", a ideia de sobrenatural sendo parte significativamente constitutiva do sistema cultural brasileiro (cf. 
VELHO, 1994) ${ }^{4}$, considera-se que uma análise sobre o modo como esses esquemas de representação incidem sobre as práticas políticas não deva ser preterida.

Disso conclui-se que um olhar sobre as realidades culturais do país passa evidentemente pela avaliação dos códigos de crença em jogo no tecido social. E, desse modo, analisar os comportamentos políticos que emergem nesse contexto demanda um olhar sobre os sistemas simbólicos que contemplam de modo mais efetivo aqueles códigos: as religiões populares ${ }^{5}$. É a partir dessa perspectiva que esse texto propõe examinar reflexivamente as interfaces entre os campos religioso e político, identificando as possíveis relações entre determinados sistemas de crença e a cultura política nacional ${ }^{6}$. Questiona-se o modo como as práticas populares (dotadas daqueles conteúdos "mágicos") influenciam as pautas de comportamento coletivo e os padrões de orientação política de determinados segmentos sociais do país.

Alguns pressupostos a partir dos quais a análise é empreendida devem ser ressaltados, visando evitar os "deslizes" interpretativos acima mencionados. Em primeiro lugar, é necessário distanciarse do viés de tonalidade etnocêntrica, cujo modelo restringe-se a interpretar as relações entre política e religião no Brasil como exemplos inequívocos de uma "excentricidade" ou "incoerência" cultural

4 Segundo Velho (1994), um sistema cultural é composto por unidades básicas indissociáveis, tais como os elementos cognitivos e afetivos, os códigos morais e de crença, que são expressos num conjunto de representações que caracteriza aquele sistema. De acordo com o autor, o sistema cognitivo próprio dos cultos populares - baseados em concepções mágicas - é amplamente compartilhado na cultura brasileira.

5 Embora o próprio conceito de religião popular demonstre-se problemático (cf. FERNANDES, 1984; MARTÍN, 2009), parece ser correto afirmar que, no país, a repartição do campo religioso em seu registro popular corresponde a certas denominações estruturadas em sistemas cognitivos contíguos àquilo que a sociologia e antropologia clássica categorizaram como próprios do "pensamento mágico". Em que pese todas as complexidades da noção de magia (cf. PELS, 2003), trata-se de formas mais individualizadas de crença, destituídas de uma ética substancialmente coletiva e orientadas à resolução dos problemas do mundo prático.

6 O conceito de cultura política é trabalhado nesse artigo de acordo com a proposição original de Gabriel Almond e Sidney Verba (1989), estando relacionado à distribuição particular dos padrões de orientação com respeito a objetos políticos entre os membros de determinadas coletividades. 
(inferida na suposta anulação do político em condições de copresença com o pensamento "mágico-religioso"). Como propôs Roberto DaMatta (1993) para o caso da cultura política, é devido lançar mão de uma perspectiva mais relativa, que apreenda as realidades observadas a partir de suas próprias circunstâncias, verificando os significados através dos quais operam e analisando as contradições culturais que expressam. Sugiro que tal proposta possa ser realizada, em primeiro lugar, a partir da conjugação entre observações estruturais (que analisam os sistemas cognitivos e sua incidência na práxis política) e situacionais (que levem em conta a experiência concreta dos atores sociais no âmbito de suas interações). Tal medida propõe viabilizar observações que se referem não apenas ao modo como um conjunto de representações incide sobre os comportamentos coletivos, mas ainda à forma como tais representações são vivenciadas na prática por parte dos atores, assim ressalvando-se as circunstâncias específicas pelas quais determinados grupos experimentam as relações entre religião e política ${ }^{7}$. Em segundo, é prudente desconstruir as categorias analíticas básicas através das quais os sistemas cognitivos estudados têm sido historicamente percebidos. Nesse caso, sugiro que o problema não consista na utilização de categorias como "magia" ou "pensamento mágico" (no que concerne à reflexão dos sistemas de representação próprios das religiosidades populares), mas na utilização dessas noções num sentido escalonar (como designativas de estágios evolutivos do pensamento humano) que desconsidere a copresença evidente de esquemas de pensamento duais - mágicos e racionais - presentes em qualquer sistema cognitivo (cf. MORIN, 1996).

A partir desses pressupostos, essa reflexão enfoca o universo empírico que concerne às religiões afro-brasileiras e segmentos neopentecostais, registros do campo religioso brasileiro, concebidos

7 Estou avaliando que a consideração da perspectiva êmica demonstra-se como decisiva para evitar visões naturalizadas acerca das relações entre política e religião. Embora este trabalho configure-se como uma reflexão de caráter ensaístico, a quantidade de dados etnográficos disponíveis na literatura especializada possibilita uma apreciação considerável de perspectivas êmicas relativas a diversas denominações do campo religioso brasileiro. 
como heurísticos das complexidades que envolvem a compatibilização entre determinadas modalidades de crença e as práticas políticas brasileiras. Como se sabe, trata-se de formas religiosas amplamente disseminadas pelos estratos populares do país e que, ressalvadas as diferenças, compartilham a crença em espíritos, na possessão, na interferência de forças ocultas junto ao mundo concreto, ainda portando forte caráter individualista e orientação mística voltada à resolução das demandas práticas do cotidiano. Ou seja, possuem aqueles elementos básicos que desvelam os sistemas de crença supostamente incompatíveis com o universo político e racional da modernidade: os sistemas cognitivos contíguos ao "pensamento mágico". Em síntese, e com base nesse recorte, importa à essa reflexão os aspectos ligados à estrutura de ideias e mentalidades inspiradas por cosmologias religiosas, em suas relações com as pautas de orientação individuais e coletivas. Tais orientações são aqui concebidas como seminais na constituição dos padrões da cultura política brasileira, seja em caráter estrito (nos procedimentos decisórios de voto), seja numa acepção extensa (na configuração da cidadania e da democracia no país).

\section{Secularização Encantada na Esfera Pública Brasileira}

Compreender as relações entre a política e a religião no contexto estudado passa por algumas considerações tanto sobre a estruturação do campo religioso do país, quanto sobre o processo de secularização, em sua versão brasileira. No Brasil, em conjunto com os procedimentos de laicização do Estado (disestablishment), engendrouse uma efervescente lógica de pluralização do campo religioso, a partir da livre-concorrência entre diversas denominações e sistemas devocionais anteriormente praticados de maneira dissimulada sob a hegemonia católica. Conforme Pierucci (2000, p. 289), tal hegemonia, até hoje operante, decorre não apenas da colonização portuguesa, mas também da catequese promovida pelos Padres Jesuítas, os missionários mais representativos da contrarreforma ibérica, tendo sido o Brasil 
um país oficialmente católico por quase quatro séculos. No período colonial, a estreita relação entre Estado e Igreja Católica se deve, primeiramente, à concessão do padroado à coroa portuguesa por parte do Vaticano, numa relação contratual em que o Estado português se comprometia com a conversão de novos fiéis, passando então a impor sua orientação às Igrejas coloniais com base numa intermediação das diretrizes advindas de Roma. Por sua vez, já no regime imperial, a partir de 1827, o padroado passa da coroa portuguesa ao controle do Imperador D. Pedro I, o catolicismo firmando-se como religião oficial do Estado brasileiro (PIERUCCI, 2000). Somente no final do século XIX, com a substituição da Monarquia pela República, o Estado é declarado oficialmente laico, embora por muito tempo tenha sido mantida uma condição oficiosa que assegurou à Igreja Católica certos privilégios ${ }^{8}$.

Se é possível considerar que a laicização do Estado favoreceu a diversificação do campo religioso brasileiro, é também pertinente avaliar que tal processo não correspondeu à lógica central evidenciada nas teorias weberianas, relativas não apenas à separação entre Estado e religião, mas ainda ao processo de "desencantamento", contido em visões de mundo cada vez mais racionalizadas - aquilo que Peter Berger (1973) denominou como "secularização das consciências". Ao contrário, como propõe Burity (2001), em primeiro lugar, observouse na modernidade tardia brasileira uma espécie de "reencantamento do mundo", lógica baseada em novas formas de aderir ao religioso e em maneiras menos institucionais de crer, as quais têm se atualizado de acordo com um trânsito constante de agentes por entre as mais diversificadas ofertas religiosas ${ }^{9}$. Assim, aquelas práticas dotadas de conteúdos "mágicos" encontraram realidades favoráveis para se adaptar à sociedade brasileira contemporânea. Em segundo lugar,

8 Para uma análise detalhada do histórico das legislações que definiram as relações entre Estado e religiões no Brasil e América Latina, ver o trabalho de Oro (2007).

9 No Brasil, esses processos foram tratados por Steil (2001) e Follmann (2007). Entretanto, a concepção de reencantamento é presente mesmo no grande berço da democracia racional europeia, vide os estudos de Hervieu-Léger (1999) e Champion (1997) sobre a correspondência do fenômeno na sociedade francesa. 
a propalada autonomia entre as esferas do religioso (privado) e do político (público) deve ser relativizada, detectando-se um eminente retorno da religião à esfera pública, especialmente a partir de uma "reabertura dos espaços públicos (institucionalizados ou não) à ação organizada dos grupos e organizações religiosas" (BURITY, 2001, p. 29). Essa reaproximação de campos anteriormente "apartados" pela razão secular se promove com base em mudanças históricas que vêm desconstruindo as fronteiras entre o público e o privado. Com o processo de pluralização cultural e religiosa, e com base numa luta por espaços de representação político-identitária (promovida por diferentes grupos culturais e religiosos, muitas vezes em conflito), não apenas o Estado brasileiro passou a ser convocado para regular as relações tensas que se engendraram, como os próprios coletivos religiosos passaram a buscar espaços de representação política, seja através de disputas eleitorais ou de iniciativas de obtenção de recursos públicos visando atividades filantrópicas ${ }^{10}$.

Essas constatações levam a três considerações importantes: (I) em primeiro, a lógica do reencantamento do mundo, conduzida por formatos menos institucionalizados e mais pessoais de crer, engendrou um campo favorável à proliferação de concepções mágicoreligiosas (mais individualistas e menos éticas), permeadas por sincretismos e bricolagens de diversos tipos, as quais já encontravam em território brasileiro uma ampla projeção desde o período colonial; (II) se a profusão desses sistemas de crença já implicaria em suposições sobre sua incidência junto aos aspectos da cultura política, a concepção inerente a um retorno do sagrado em meio aos espaços de representação política próprios da esfera pública, especialmente a partir da redemocratização brasileira dos anos 1980, corrobora ainda mais com a constatação dessa pertinência; (III) finalmente, essas duas considerações acabaram por fomentar as matrizes interpretativas

10 São exemplares aqueles casos em que, a partir de reivindicações identitárias, comunidades de culto religioso pleiteiam recursos públicos com propósitos de preservação de suas tradições culturais (BURITY, 2008). 
que referiram a cultura política brasileira como tipificação de um contexto moderno inacabado, numa relação em que a proliferação de conteúdos mágicos estaria diretamente relacionada a uma práxis política personalista, clientelista e paternalista ${ }^{11}$. Nessas matrizes, categorias como essas estariam supostamente ligadas aos aspectos individualistas e não éticos presentes nos cultos de acepção mágica, cuja expressão máxima poderia ser referida nas relações de "troca" presentes em universos religiosos e políticos: as trocas devocionais, comuns nas relações entre adeptos e divindades da religiosidade popular, e seu correlato político: o clientelismo estabelecido entre atores políticos e agentes sociais diversos.

No entanto, antes de realizar a crítica dessas interpretações e contribuir com as explicações alternativas ao tema, é devido recuperar um pouco do histórico das práticas religiosas aqui estudadas concebidas como heurísticas das relações colocadas em análise. Tratase de promover um mapeamento tanto de aspectos cosmológicos, quanto da presença dos agentes ligados a essas religiosidades na esfera política. Desse modo, três categorias aqui concebidas como relevantes serão colocadas em evidência: (I) as premissas ético-morais contidas em cada sistema de crença; (II) a configuração do modelo de "sujeito" que emerge nos esquemas cognitivos avaliados; (III) a participação direta dos agentes religiosos ligados aos campos afroreligioso e neopentecostal na esfera pública brasileira.

\section{Religiões Afro-Brasileiras}

As religiões afro-brasileiras configuram uma das facetas mais "mágicas" do campo religioso do país. Trata-se de religiões iniciáticas, com forte presença de elementos emocionais, destacando-se o êxtase religioso expresso na possessão. Em geral, são religiosidades que

11 Como exemplo dessas tendências analíticas, ver os trabalhos de Prandi (1996) e Negrão e Concone (1985) sobre as religiões afro-brasileiras, bem como os estudos de Mendonça e Velasques Filho (1990) e Rolim (1985) sobre o campo evangélico mais amplo e suas vertentes pentecostais. 
se utilizam de práticas sacrificiais como elemento mediador entre realidades sagradas e profanas, adotando sistemas oraculares como forma de interpretação e ordenamento simbólico do cotidiano de adeptos e simpatizantes. Sacrifícios, oferendas, oráculos e divindades sobrenaturais correspondem a elementos que podem interferir diretamente na vida dos agentes. Mediante a manipulação desses mecanismos, observam-se atividades religiosas voltadas a resultados práticos e orientadas à resolução de diversificadas demandas, com destaque para as questões econômicas, emocionais e de saúde, características que favoreceram sua interpretação como "religiosidades de aflição" (FRY; HOWE, 1975).

Essas formas religiosas surgem no território brasileiro a partir daintroduçãodoelemento africanono sistema escravagista, adaptandose de modo distinto em cada região do país, onde estiveram submetidas a processos de troca cultural específicos. Assim, desenvolveram-se como Candomblé na Bahia, Xangô em Pernambuco ou Batuque no Rio Grande do Sul ${ }^{12}$. Apesar dos traços diferenciais, todas mantêm características comuns como o uso majoritário da linguagem ritual iorubana, as práticas sacrificiais e a possessão pelos orixás - divindades que compõem os panteões. Inicialmente concebidas como "religiões étnicas", tais práticas se universalizaram, sendo hoje frequentadas pela população branca e por indivíduos de diversificados estratos sociais (PRANDI, 1991) - embora, na grande maioria dos casos, ainda se revelem como cultos radicados nas periferias das grandes cidades brasileiras (BRUMANA; MARTÍNEZ, 1991).

A adaptação mais ocidentalizada que compõe a multifacetada categoria "religiões afro-brasileiras" denomina-se Umbanda. Surgida no sudeste brasileiro em meados da década de 1910, constitui uma fusão de traços de matriz africana, espíritas, indígenas e católicos, sendo baseada numa iniciativa de codificação teológica

12 O estudo mais completo e abrangente sobre as religiões de matriz africana no país foi elaborado Roger Bastide (1960), que pesquisou exaustivamente as particularidades de cada adaptação nas diferentes regiões brasileiras. 
que visou refutar traços socialmente concebidos como "primitivos" em acordo com o preconceito da sociedade envolvente (ORTIZ, 1978). Rumando a uma racionalização de seus conteúdos éticos e cosmológicos, aboliu o sacrifício de animais e adotou uma ética da caridade típica do cristianismo (NEGRÃO, 1996), conquistando uma impressionante aceitação social no país entre as décadas de 1950 e 1960. No entanto, na medida em que recusou certos elementos como a imolação de animais, acabou por valorizar esses mesmos traços como simbolicamente eficazes na resolução de problemas aflitivos, assim perdendo espaço em relação aos cultos mais africanizados, que se tornaram hegemônicos no campo afro na década de $1970^{13}$. Devido a esses fatores, denominações mais africanizadas como Candomblé, Xangô e Batuque acabaram adotando práticas umbandistas por sua maior aceitação social, enquanto sacerdotes da Umbanda aderiram às práticas mais tradicionais em função da referida eficácia mística. Atualmente, a maioria dos templos afro-brasileiros possuem uma configuração mista, observando-se uma sobreposição de vertentes praticadas numa mesma unidade de culto, agregando-se Umbanda e alguma das denominações mais africanizadas (PRANDI, 1991).

Um fator importante se refere à impossibilidade de culto aos antepassados das famílias africanas na adaptação brasileira dessas religiosidades. Conforme demonstrou Prandi (2000), seriam as divindades dos clãs africanos aquelas que detinham autoridade moral sobre os adeptos. Com o desaparecimento dessa dimensão em decorrência da dissolução da família negra no escravismo (ao menos nos moldes africanos) ${ }^{14}$, a tarefa de moralização do elemento

13 Esse processo tem sido interpretado pela literatura especializada como lógica de "reafricanização" das religiões afro-brasileiras (cf. CAPONE, 2004), o que inclui, além da ressignificação de aspectos rituais e cosmológicos, diversas estratégias de reposicionamento identitário entre os adeptos do campo afro-religioso.

14 Alguns estudos históricos têm promovido uma severa crítica às considerações sobre a ideia de "desagregação" familiar negro-africana na sociedade escravocrata (cf. SLENES, 1988), referindo a formação de relações conjugais estáveis desconsideradas por olhares etnocêntricos. Em que pese a preciosidade dessas análises, não é possível desconsiderar a impossibilidade da manutenção das sociedades de linhagens em contextos escravistas, o 
negro no Brasil colonial seria provida com base num sistema jurídico já estabelecido e em conformidade com as tradições judaico-cristãs, então hegemônicas no país. Ressalte-se aqui, como bem observou Pierucci (2000, p. 301), que os orixás (divindades de comunidades amplas), ao contrário dos ancestrais, não configuram deuses moralistas que condenam ou castigam o mal. Desse modo, correspondem a um oposto da perspectiva teológica contida nas religiosidades surgidas da palavra e da ação dos grandes profetas, cuja ideia basilar se assenta na regulamentação ética e moral da vida cotidiana dos agentes religiosos. Assim, nos modelos afro-referenciados, a dimensão ritual tende a ser decisivamente enfatizada, e como corroborou Prandi (2000, p. 77), "podem ser caracterizadas como religiões rituais cuja dimensão mágica supera em muito a dimensão que diz respeito aos aspectos morais [...]". Nesse contexto, tais religiões já nascem no Brasil como práticas individualistas e sem um repertório moral estabilizado ${ }^{15}$. Cada unidade de culto se desenvolve com ampla autonomia e o forte conteúdo mágico favorece a constituição de inúmeras agências de serviços religiosos.

Em geral, os cultos são estruturados com base numa figura centralizadora (o pai-de-santo) e seus iniciados (filhos-de-santo), na concepção de uma grande família mística na qual o adepto tornase filho espiritual de seu iniciador e irmão dos outros componentes do templo. Na cosmovisão afro-religiosa, cada iniciado ainda é filho mítico de um orixá, com o qual mantém relações indissociáveis ao

que incide de maneira efetiva na estruturação da crença aos antepassados nas religiões afrobrasileiras. É importante avaliar que, em contextos de diáspora, o culto aos antepassados clânicos fora não apenas dificultado, como incidiu diretamente nas representações morais articuladas nas religiosidades negras.

15 Não se está propondo aqui a ausência de vínculos gregários e de solidariedade entre os adeptos dessas religiões, cujas formas sociais próprias forneceram a amplas camadas da população negra as lógicas de pertença fundamentais para a resistência em relação às opressões do período pós-escravagista (cf. LODY, 1987). Ao se assinalar que essas práticas se organizam a partir de parâmetros individualistas se está apenas referindo um padrão de sociabilidade característico e percebido de modo recorrente pela antropologia especializada, o qual emerge no campo dos terreiros como modelo preponderante na organização dos papeis sociais e suas relações decorrentes (cf. CORRÊA, 1998). 
longo da vida e trajetória religiosa. É essa divindade que lhe protege no cotidiano e a ela se deve oferendas e sacrifícios esporádicos como forma de reatualização dos vínculos místicos. A identidade pessoal de cada iniciado é construída com base numa combinação entre suas próprias características e as simbologias associadas às divindades que lhe dizem respeito, as quais possuem diferentes personalidades e estereótipos (geralmente retratados nas narrativas mitológicas que revelam o passado vivido de cada orixá). Desse modo, como observou Goldman (1985), as religiões de matriz africana fornecem padrões de comportamento que modelam, ajustam ou legitimam as atitudes do fiel em sua práxis cotidiana, como um processo de validação social de condutas que a pessoa possui ou deseja possuir. $\mathrm{O}$ sujeito que emerge nessa pertença pode ser concebido como extremamente "descentrado": na medida em que os padrões de comportamento são ajustáveis, e que a inexistência de códigos morais precisos não restringe tais possibilidades, pode-se ser aquilo que se deseja. Os tabus e interdições presentes nos códigos afro-religiosos se limitam à relação entre indivíduo e sua divindade correspondente.

$\mathrm{O}$ processo de desenvolvimento dessas religiosidades no país foi promovido em conjunto com uma extrema repressão social, primeiramente promovida pela Igreja Católica e pelo Estado, que visou coibir práticas então associadas ao "curandeirismo" e à "feitiçaria". Mais recentemente, atitudes persecutórias passaram a ser empreendidas por segmentos evangélicos, numa disputa acirrada pelos consumidores de serviços mágico-religiosos. Como iniciativas de reação a tais realidades, sobretudo a partir da maior liberdade religiosa no país, os adeptos dos templos africanistas passaram a organizar-se a partir de instituições federativas e, de sobremaneira, apostando em candidaturas a cargos públicos. Entretanto, como diversos estudos vêm ratificando, esses empreendimentos na arena política não apresentam êxito. Algumas pesquisas realizadas mais especificamente no Rio Grande do Sul têm verificado na competição interna, na descentralização de poder e na fragmentação do campo 
africanista os principais motivos dos insucessos eleitorais (cf. DE BEM; LEISTNER, 2010; ORO, 2001, 2008). Decerto, o fracasso eleitoral dos representantes dessas religiões se conectaria ainda àquelas lógicas inerentes a uma pertença individualizada e descentrada, fomentada pela visão de mundo afro-religiosa, a qual dificultaria ações coletivas e projetos políticos comuns. No que se refere às possíveis tendências dos adeptos dessas religiões nos processos ligados a uma práxis política mais ampla, de acordo com a interpretação mais recorrente sobre essas realidades (PRANDI, 1996), a dimensão não-ética e o individualismo descentrado sugeriria possibilidades compatíveis com as relações clientelísticas e personalistas existentes no país.

\section{Religiões Neopentecostais}

As religiões neopentecostais emergem no Brasil em acordo com a constante pluralização das tendências cristãs, configurandose como um dos principais troncos do protestantismo brasileiro. $\mathrm{O}$ segmento protestante surge no Brasil no século XIX, com a chegada do luteranismo introduzido pelo expressivo contingente de imigrantes alemães, especialmente nos estados do Rio Grande do Sul e Santa Catarina, a partir de 1824 (cf. PIERUCCI, 2000). Como é sabido, desde o Século XX o protestantismo se divide em duas categorias principais: "históricos" e "pentecostais". Os protestantes históricos se subdividem entre o protestantismo de imigração e o protestantismo de conversão. Os primeiros, Luteranos, Anglicanos e Metodistas, designam a tendência mais próxima ao ramo original da Reforma, trazido ao país pelos imigrantes europeus. Os segundos, Presbiterianos, Batistas e Episcopais, referem-se às tendências que aportaram no Brasil a partir do trabalho de missionários que chegavam dos Estados Unidos com a finalidade de converter os brasileiros.

Por sua vez, os protestantes pentecostais começam a se manifestar no país com o surgimento dos primeiros templos no início do Século XX, configurando-se como herdeiros dos movimentos 
revivalistas que tiveram início nos Estados Unidos, em fins do Século XIX (BRUMANA; MARTÍNEZ, 1991). Baseados no fenômeno bíblico de pentecostes, estruturam-senoBrasil sob inúmeras denominações, sendo o segmento que mais cresce no campo religioso nacional (MARIANO, 2004). Algumas diferenciações entre as denominações existentes passaram a fornecer uma classificação radicada em duas tipologias básicas: os pentecostais tradicionais, cujos exemplos se referem às Igrejas "Assembleia de Deus", "do Evangelho Quadrangular" e "Deus é Amor"; e os neopentecostais, que se destacam como forma religiosa mais representativa entre todos os segmentos protestantes brasileiros, sendo a que mais cresce e mais agregou concepções mágicas em suas elaborações simbólicas, assim distanciando-se das formas originárias contidas no protestantismo europeu.

Destaque-se que a incorporação desses elementos parte inclusive de uma cooptação de signos das religiões afro-brasileiras, em dinâmicas mimeticamente produzidas nos processos de reposicionamento identitário próprios do campo religioso brasileiro (cf. ORO, 2006). Nesses termos, o neopentecostalismo vem agregando os elementos centrais daquelas cosmologias, como a crença na possessão e na feitiçaria, os quais são ritualmente ressignificados em empreendimentos quevisam seapropriardossistemas demediaçãocom o sobrenatural, especialmente aqueles considerados simbolicamente eficazes por amplas parcelas da população (cf. SILVA, 2005). Como bem lembrou Oro (1997), essa apropriação decorre de uma disputa pelo mesmo espectro do mercado religioso, as classes populares, o que por sua vez demandou a incorporação de elementos valorizados pelas camadas consumidoras dos serviços mágicos disponíveis. Algumas denominações importantes do neopentecostalismo atual designam a "Igreja Internacional da Graça de Deus", "Igreja Nova Vida" e "Renascer em Cristo".

Entretanto, a vertente que projeta maior representatividade no campo político brasileiro atual corresponde à "Igreja Universal do Reino de Deus". Fundada no Rio de Janeiro em 1977, a IURD apresenta 
hoje um crescimento exponencial, tanto em número de adeptos quanto em termos de empreendimentos institucionais. Organizada a partir de forte estrutura administrativa e mercadológica, utilizando sofisticadas estratégias de marketing, a IURD detém um invejável crescimento econômico, dispondo de inúmeros templos espalhados pelo país e de um império midiático composto por emissora de televisão, jornal impresso de circulação nacional e algumas emissoras de rádio ${ }^{16}$. Com base nesse poder econômico e editorial, desde a década de 1980 inseriu-se nas disputas da arena pública visando obter maior representatividade política, demonstrando uma eficácia políticoeleitoral especial e elegendo um forte contingente de candidatos no legislativo do país.

Conforme Pierucci (2000, p. 296), essas práticas elaboraram conteúdos religiosos eficientes em termos práticos, voltados a soluções para a vida cotidiana dos adeptos, sendo pouco exigentes em sentido ético e descomplicadas do ponto de vista doutrinário. Conservam do pentecostalismo clássico as tendências fortemente emocionais, voltadas para o êxtase, destacando-se a glossolalia, o exorcismo e o milagre, experimentados como resultados imediatos na vida dos convertidos. Nesse sentido, um conjunto de elementos mágicos é ressignificado e somado à doutrina neopentecostal originária, agregando banhos fluídicos e queima de incensos, além das readaptações do transe mediúnico importado dos terreiros afro.

Ari Oro (1997) refere que essas religiões organizam-se a partir de uma compreensão de mundo binária e fortemente amparada na constante tensão entre os demônios (causadores do mal) e Deus (caudatário absoluto do bem). Como recorda Prandi (2003), se os demônios são responsáveis pelo mal, e se a ação diabólica está por toda a parte no mundo, a ética contida nessas práticas conduz a um dualismo entre bem e mal no qual o compartilhar do bem só é possível com base na recusa do mundo concreto. Tal abdicação é processada

16 Para uma análise mais profunda dos empreendimentos e estratégias de expansão da Igreja Universal do Reino de Deus no Brasil, ver a análise de Campos (1999). 
quando o indivíduo se afasta da esfera profana, resguardando-se junto ao universo simbólico codificado pela doutrina e interpretado pelo pastor. A partir dessa perspectiva, o dinheiro passa a ser visto como produtivo para a ampliação da obra de Deus e a política como espaço para o combate às corrupções do demônio. No entanto, como economia e política correspondem a esferas mundanas, devem ser gestadas pelos sacerdotes, os quais receberão o dízimo e cooptarão uma esmagadora parcela de eleitores distribuídos pelos quadros sociais das Igrejas.

Essas considerações projetam duas matrizes através das quais é possível pensar os códigos éticos e os possíveis sujeitos que emergem nas pertenças pentecostais. Com base nessa ética binária do bem e mal absolutos, que propõe a rejeição do mundo e sua administração pelo corpo sacerdotal estratificado, observa-se uma combinação infrequente que aponta uma espécie de "individualismo holista". O indivíduo deve agir segundo os padrões individualistas do capitalismo moderno visando prosperar economicamente e fornecer sustento à obra divina, ao mesmo tempo em que necessita obedecer a uma hierarquia rígida na qual apenas os pastores o conduzem ao caminho do bem. O sujeito é indivíduo no mundo profano, pois é competitivo e detém suas demandas pessoais atendidas pela eficácia mágica oferecida nos cultos. Entretanto, se encontra hierarquicamente situado numa coletividade unificada pela institucionalização rígida das experiências religiosas.

No que se refere à presença do neopentecostalismo na arena pública e no campo político, seu proselitismo exacerbado levou a uma contundente expansão dessas denominações, e um dos principais mecanismos de institucionalização e ocupação de espaços sociais tem sido a eleição de representantes para a sociedade política. Segundo Ari Oro (2003), o sucesso eleitoral dos candidatos neopentecostais, sobretudo aqueles ligados à Igreja Universal do Reino de Deus, decorre de uma combinação de fatores como o carisma institucional e o extensivo uso do aparato midiático e dos recursos administrativos 
disponíveis. A combinação desses recursos opera através de uma centralização hierárquica coesa e de um modelo próprio de fazer política, que inclui desde o apoio a candidatos laicos, até o lançamento de candidaturas religiosas oficiais. Em geral, os candidatos da Igreja são escolhidos após pesquisas realizadas nos quadros de adeptos e suas campanhas contam com todos os recursos disponibilizados pela instituição. Assim, não são raros os recenseamentos endógenos visando obter os dados eleitorais dos fiéis, bem como as campanhas de conscientização sobre o exercício do voto. Em síntese, trata-se de uma das principais instituições brasileiras a se dedicar à gestão do voto de seus membros (ORO, 2003).

No plano simbólico discursivo, observa-se a ideia de tornar o universo político sacralizado, com vistas a eleger homens de Deus capazes de contrapor a diabólica corrupção que assola o país. Assim, a ética da diabolização torna-se a principal estratégia discursiva para a conclamação dos fiéis ao voto, embora o combate direto aos males do político, a ser executado na esfera pública, esteja acessível somente a um corpo sacerdotal habilitado. Ainda em conformidade com o trabalho de Oro (2003), a projeção política da Igreja Universal traz consequências tanto ao campo religioso quanto ao campo político do país. Por um lado, produz um efeito mimético em outras denominações religiosas, que procuram reproduzir suas estratégias; por outro, transforma-se num foco de interesse dos partidos políticos, que a partir do poderoso capital político das Igrejas objetivam a promoção de alianças e pactos, geralmente conjugados em relações aparentemente contingentes.

\section{Religiões Populares E Cultura Política No Brasil: Das Análises Estabilizadas A Um Exercício De Relativização}

Nas análises mais estabilizadas sobre a relação entre política e religião na sociedade brasileira, as realidades do campo religioso puderam facilmente encontrar correspondência na práxis política do país. Autores como Mainwaring (2001) identificaram o que 
poderia ser compreendido como as significações estruturais da práxis política brasileira, organizadas num comportamento político do tipo personalista e pragmático. Tanto as dimensões político/ administrativas apresentam uma matriz lógica fortemente impregnada pelo clientelismo quanto encontram sua manutenção nos processos decisórios, numa realidade que expressaria os limites da democracia brasileira. A relação entre a elite política e seus contingentes eleitorais ocorre por meio de barganhas, negociações informais e relações paternalistas, centradas nos aspectos particularistas contrários à universalização de direitos -concepção básica do projeto democrático liberal.

Tal tendência seria fomentada à medida que recebe sustentação nas bases populares, para as quais o clientelismo corresponderia à única forma de assegurar os benefícios historicamente direcionados a segmentos restritos da população. Para os efeitos da argumentação aqui desenvolvida, o que se demonstra pertinente seria a relação dialógica entre um processo democrático comprometido em virtude dessas relações particularistas e sua correspondência com as lógicas culturais embasadas em determinados modelos cognitivos, cujas concepções éticas se ajustariam às relações pessoalizadas da cultura política vigente. Num quadro interpretativo convencional, a expansão das práticas mágico-religiosas evidenciaria não apenas a expressão daquelas realidades políticas, como também forneceria a sedimentação simbólica das mesmas.

Essas possibilidades interpretativas tornar-se-iam ainda mais evidentes quando aprofundadas as características dos sistemas cognitivos que ordenam as religiosidades populares aqui estudadas. Como advertiu Paula Montero (1994), é sobretudo nos estudos da sociologia e antropologia clássica de Durkheim (1993), Frazer (1956) e Lévy-Bruhl (2008) que o pensamento mágico obteve uma categorização tipológica, especialmente em relação a três traços principais: (I) sua associação com a ausência de responsabilidade moral; (II) o forte individualismo e o descentramento dos sujeitos; (III) sua identificação 
com uma racionalidade supostamente "pré-lógica" e "incapaz" de constituir representações objetivas. Com base nesse marco teórico, os aspectos característicos de uma cultura popular permeada pela magia comportariam ao menos dois desses traços em evidência, os quais ratificariam as problemáticas da democracia brasileira e da práxis política clientelística e paternalista.

Como fora argumentado, no caso das religiões afrobrasileiras, a inexistência de codificações éticas abrangentes solidifica a possibilidade de padrões de comportamento ajustáveis, o que desvela a possibilidade de descentramento dos sujeitos praticantes. Isso explicaria as dificuldades que tais grupos encontram na consolidação de projetos políticos comuns, vide o exemplo da não eleição de seus representantes na arena política. Nesse caso, observase um individualismo exacerbado e descentrado, de conotações "póséticas" compatíveis com uma realidade social na qual tudo vale em nome da própria realização das expectativas e demandas pessoais. Por outro lado, no caso do neopentecostalismo, a ética dicotômica (bem versus mal absoluto) é o que se conecta com a constituição de sujeitos que transferem sua autonomia política para o controle de seus sacerdotes. No caso, evidencia-se uma espécie de perspectiva "préética", na qual a recusa do mundo do pecado conduz à contraditória lógica da participação política intensa e ao mesmo tempo pouco autônoma, acrescida da mistura de um "individualismo holista", que desfaz qualquer noção de centralidade/responsabilidade do sujeito. Em ambos os casos, a fraca consolidação ética e a perspectiva de sujeitos descentrados não conduziria à consideração de condutas compatíveis com as expectativas liberais democráticas. O que pode ser percebido é que as lógicas de clientelismo e paternalismo da política do país estariam fartamente amparadas em sistemas de crença que ora fomentam a individualidade e personalização das relações, ora relegam a autonomia política aos líderes carismáticos.

Na análise de Prandi (1996), algumas tendências desse modelo interpretativo serão recorrentes. Segundo o autor, o florescimento da 
magia em meio à sociedade moderno-secular consiste numa reação ao mundo desencantado das instituições burocráticas e racionais, no qual os aspectos tradicionais e pré-capitalistas vêm conquistando cada vez mais espaço. Assim, a cidade moderna, onde tudo é desencantado e não religioso, seria o espaço no qual se exige um comportamento sempre fundado naquela razão que advertia sobre os avanços econômicos e políticos, mas cuja realidade nunca fora estendida a todos. Brasileiros pobres e desempregados, imersos numa realidade social cheia das tensões advindas da violência urbana e da insegurança socioeconômica observaram o fracasso das promessas modernas de distribuição de benefícios sociais. Contudo, nesse contexto, os desamparados poderão contar apenas com deuses, mas deuses de todos os tipos e ritos, fartamente encontrados naquela mesma cidade (cf. PRANDI, 1996, p. 28).

Ainda segundo esse autor, embora as vertentes religiosas de caráter mágico mantenham diferenças em relação ao comportamento político de seus adeptos, bem como em seus modos de aproximação com a esfera pública, todas sinalizariam uma inequívoca relação na qual uma cultura política pouco democrática se estabelece: por um lado, as promessas da modernidade não alcançaram todos os segmentos da sociedade e assim se favoreceu o florescimento da dimensão mágica necessária à reorganização das experiências identitárias daqueles indivíduos alijados do processo de modernização; por outro, esta proliferação da magia sustentaria as tendências personalistas e clientelísticas, fomentando uma cultura política de bases democráticas debilitadas. Para Prandi (1996), autor básico dessa matriz interpretativa, o quadro relativo às práticas religiosas populares e à política brasileira sinalizaria o seguinte axioma: o Brasil está mais perto da magia e, de modo reverso, distante da política.

Como pode ser constatado junto a esse modelo de análise "convencional", se o país está imerso em magia e, por conseguinte, distante do político, corrobora-se com as perspectivas que asseveram a incompletude da modernização do país. O que deve ser destacado é 
que as orientações teóricas que procuram analisar a interface entre a cultura política brasileira e seus aspectos religiosos, tanto a partir de numa apropriação do conceito de secularização de Max Weber (1994) quanto através das categorias do pensamento mágico formuladas pela antropologia e sociologia clássica, apenas serão capazes de reproduzir e confirmar as constatações sobre o afastamento das realidades observadas junto a um determinado padrão cultural, que definitivamente é alheio às realidades brasileiras. Numa ótica ainda mais radical, e por certo mais problemática, poder-se-ia sugerir que a característica da suposta "mentalidade pré-lógica" contida nos esquemas cognitivos populares conjugaria todos esses fatores e encerraria qualquer possibilidade do projeto democrático no país.

Não se trata de afirmar que, por vezes, tais análises não encontrem reciprocidade empírica. Decerto, os sistemas de crença articulados junto às religiosidades populares tanto podem influenciar no estabelecimento das relações clientelísticas quanto são, por vezes, fomentados pela fraca consolidação dos direitos sociais no país. Há nisso uma relação recíproca, na qual o pensamento religioso pode favorecer um modelo de cultura política e vice-versa. Contudo, o problema não se refere apenas aos diagnósticos formulados, que naquelas análises soam um tanto parciais. O que está sendo sugerido é que, em primeiro lugar, o esquema de inferências sobre esses diagnósticos não deve ser elaborado a partir de modelos de análise fundamentados em comparações entre diferentes sistemas, sob pena de empobrecer a compreensão das realidades observadas em seus aspectos mais específicos. Disso decorre que uma agenda de pesquisa seria mais fecunda ao não se restringir a perspectivas teóricas constituídas no marco epistêmico "moderno", o qual, na maioria das vezes, reproduziu a dualidade atraso/progresso e fomentou concepções normativas. Ora, há muito se sabe que no Brasil existe clientelismo e patronagem. Resta sim, identificar o que esses sistemas expressam no interior da própria cultura brasileira. 
Em segundo lugar, se nosso esquema de inferências se desloca para a observação das particularidades de um sistema cultural, em suas especificidades, é possível que os próprios diagnósticos ultrapassem uma visão inequívoca (e por essa razão parcial) acerca de supostas incoerências, tanto no que se refere à presença da magia na sociedade brasileira contemporânea, quanto em relação a uma correspondência aparentemente direta entre uma práxis política ancorada no personalismo e o pensamento mágico disseminado no campo religioso do país. Dito de outro modo, sugere-se aqui que tais realidades devam ser relativizadas, sendo prudente refleti-las mediante suas lógicas e contextos próprios de operacionalização.

É nesse propósito que DaMatta (1993) empreendeu uma análise da cultura política brasileira observada mediante suas próprias especificidades. Conforme refere o autor, a grande pobreza epistêmica das observações sobre o país origina-se no fato de que os analistas raramente discutem seus referenciais, os quais são tomados de modo apriori como lógicos e precisos, sendo os mesmos componentes de um sistema definível em categorias como modernidade, capitalismo e progresso. No entanto, deve-se ressaltar que tais categorias são formuladas pelo próprio observador, e dessa maneira, tornam-se peso e medida de sua própria análise. Assim, a realidade política brasileira tende a ser vista como carente de linearidade, como se o pressuposto de qualquer análise fosse o de detectar uma história similar às realidades do norte ocidental, constituídas por meio da acumulação de instituições que substituíram suas predecessoras. É nesse marco analítico que se tende a compreender a cultura brasileira (em termos políticos e mágico-religiosos) como mescla incoerente de instituições; uma fusão excêntrica entre o público e o privado, a qual se amplia nas tendências do patrimonialismo e do clientelismo político.

Como propõe DaMatta (1993), ao invés denos impressionarmos com essas "estranhas concomitâncias", devemos nos ater a categorias que nos permitam estabelecer as conexões e relações existentes entre as diferentes lógicas que circulam pela sociedade brasileira. A questão 
consiste em demonstrar que os elementos empíricos de cada contexto são experimentados, historicamente, de forma diversa. No que se refere ao padrão democrático que se tem por "modelo", torna-se coerente projetá-lo como parte de realidades empíricas variadas (pois a variedade é parte da "natureza social"), cuja diversidade encontrase orquestrada num só credo ou sistema de valores: o igualitarismo liberal racional. No entanto, a aparência de ordem e coesão desses sistemas apenas opera em torno de uma moldura ideológica que torna ilegítimas outras realidades políticas. Por esse prisma, o que caracteriza a cultura política brasileira seria a ausência de necessidade em legitimar sua ordem, e a lógica de suas práticas personalistas expressam nada mais do que um sistema de recusa a certas coerências importadas dos sistemas alheios. O que DaMatta (1993) propõe é que, no Brasil, tradição e modernidade não se excluem, compondo uma oposição hierárquica e complementar que possui a trágica capacidade de compensar as injustiças do sistema. Numa complexa gramática das passagens entre a casa (o privado) e a rua (o público), engendra-se um modo próprio de navegar pelo social, através do qual é possível ser liberal e ao mesmo tempo prestar favores. Como argumenta o autor, há uma luta entre os níveis formais e informais do sistema, que se revela como espécie de solução cultural destinada a suplantar os conflitos engendrados num país em que as lógicas particularistas conviveram apenas mais tardiamente com a ordem universalista. Nessa perspectiva, há um encontro dos dois modelos, e a modernidade não levou à desarticulação dos mecanismos tradicionais, mas a formas de compatibilização entre essas tendências.

Esses mesmos parâmetros servem de base para uma análise da conservação e reprodução das religiosidades mágicas no país. De antemão, é devido avaliar que o pensamento mágico não corresponde à incapacidade de absorção de perspectivas racionais por parte de um dado sistema. Aliás, Evans-Pritchard (2005) já mostrara que entre os Azande, do Sudão de colonização recente, a crença generalizada na bruxaria não significava apenas uma vivência impregnada pelo 
misticismo, mas uma explicação para os infortúnios que não ignorava as relações entre causa e efeito, também admitidas e consideradas. Com essa demonstração, Evans-Pritchard (2005) sobrepôs possibilidades de diferentes lógicas cognitivas num mesmo sistema cultural, percebendo as relações de complementaridade das lógicas pelas quais se valiam os Azande. O que parece ter relações com a magia presente nas religiões populares e na cultura brasileira é que, assim como na práxis política, a mistura entre o público e o privado são complementares e expressam as dramáticas contradições do sistema. $\mathrm{O}$ intercâmbio entre magia e racionalidade sinaliza as soluções cognitivas necessárias para a percepção de uma complexa realidade social para a qual a racionalidade pragmática não encontrou todas as soluções ${ }^{17}$.

Contudo, deve-se considerar que também é enganoso imaginar que o pensamento mágico opera na sociedade contemporânea em seu estado puro. Como recupera Montero (1994), no Brasil a magia se tornou moderna através de dois processos: a crise da modernidade e a racionalização da magia. Tais operações ocorrem através das condições de pluralização e competição do campo religioso brasileiro, nos quais os sistemas religiosos em posição de equivalência se tornam interlocutores de um acirrado debate, numa luta de caráter eminentemente político em que se confrontam formulações de categorias cognitivas que devem produzir confiabilidade. Para tanto, as crenças devem se submeter a processos cognitivos de validação das argumentações que adentram o debate, devendo obter consenso em torno das proposições confrontadas. Como conclui Montero (1994), no contexto brasileiro, não é possível contrapor magia e racionalidade, pois as crenças mágicas, em sua operacionalidade concreta, estão perpassadas pela mesma lógica da racionalidade concorrencial que organiza a sociedade como um todo. O caráter concorrencial do campo religioso obriga os agentes a saírem do confortável lugar das doxas

17 A afirmação de que a magia seria apenas factível numa sociedade de "modernidade incompleta" corresponde a uma incapacidade de percepção quanto à presença dos misticismos que emergem atualmente nos próprios redutos originários da democracia moderna, caso do contexto francês analisado por Hervieu-Léger (1999) e Champion (1997). 
para constituir consensos em torno da validade de suas proposições ou práticas. Nessa mesma lógica, através do discurso dos idiomas rituais, o crente pode interiorizar as atitudes básicas exigidas no exercício da cidadania política.

Tal proposição não destoa daquilo que pode ser percebido como parte da perspectiva êmica, aqui considerando-se a visão que os próprios atores religiosos detém sobre as relações entre a política e a religião. Dito de outro modo, os dados etnográficos atualmente levantados em comunidades afro-religiosas e pentecostais sugerem que as experiências sociais que concernem ao cotidiano dessas práticas confirmam a fertilização mútua entre perspectivas mágicas e racionais, especialmente através de linguagens rituais atualizadas na interface dos universos político e religioso.

Um exemplo recolhido das investigações sobre as religiosidades afro-brasileiras, com base nas etnografias de Cordovil (2014), é assertivo. Nesse caso, observa-se na trajetória dessas práticas um movimento que demonstra o modo como os idiomas rituais foram se racionalizando a partir das disputas do campo religioso brasileiro. Em virtude de tensionamentos com instâncias repressivas, como outros coletivos religiosos ou o próprio Estado brasileiro, os adeptos dos cultos de matriz africana desenvolveram gradativamente diferentes modelos de combate àquelas lógicas opressivas. Se no período do recente pós-escravismo tais estratégias ainda se resumiam às guerras místicas endereçadas aos inimigos políticos (o recurso à feitiçaria como mecanismo de nivelamento das relações de poder assimétricas $)^{18}$, com a pluralização do campo religioso brasileiro e com a abertura de novos espaços políticos, após o processo de redemocratização do país, esses atores desenvolveram novos formatos associativos, visando estabelecer projetos políticos comuns (assim atenuando o forte teor individualista desse segmento na busca pela

18 Para aprofundar as discussões sobre a feitiçaria como mecanismo de nivelamento das assimetrias de poder entre afro-religiosos e outros segmentos sociais no Brasil, ver o trabalho de Corrêa (1998). 
legitimidade social). Como propõe Cordovil (2014), em função de suas necessidades de legitimação social, atualmente esses grupos chegam a ocupar os diversos canais disponíveis para a participação popular na esfera pública brasileira - como conselhos, fóruns e instâncias de deliberação política -, constando-se um histórico que se deslocou da instrumentalização ritual da feitiçaria para a participação política cidadã. E como descreve Leistner (2011), não se trata apenas da substituição do código do feitiço por metodologias burocráticas, mas da conciliação de ambas as perspectivas como recurso político. Para os adeptos dessas práticas, os recursos mágico-religiosos e a política não se configuram como realidades totalmente apartadas.

Decerto, o que tais dados revelam corresponde justamente àquelas lógicas de racionalização da magia na sociedade brasileira descritas por Montero (1994). Trata-se de perspectivas através das quais tanto a magia se racionaliza quanto o pensamento racional se torna mágico, e no caso das relações entre religião e política, a política adquire conteúdos religiosos na mesma medida em que a religião se torna politizada. Em síntese, pode-se sugerir que a presença da magia na sociedade brasileira contemporânea, constada na amplitude dos cultos religiosos populares, é menos um sinal de irracionalidade e incompatibilidade política do que uma copresença de esquemas cognitivos complementares, o que é próprio da arquitetura do pensamento humano. Tal abordagem já foi desenvolvida por Edgar Morin, que concebeu a existência de uma relação equilibrada entre pensamento mágico e racional, os quais se complementam e interagem "como se tivessem uma necessidade permanente um do outro" (MORIN, 1996, p. 144).

\section{Conclusões}

Como bem avaliou Oro (2007), no contexto latino-americano, malgrado o caráter secular da atividade política, as fronteiras entre os campos político e religioso encontram-se matizadas e se articulam por 
diversos e inusitados ângulos. No Brasil, essas conexões se processam, em parte, na aproximação de diversos segmentos religiosos junto à esfera pública, em empreendimentos nos quais políticos e grupos religiosos visam assegurar benefícios em causa própria. No que concerne às reflexões desse texto, tais conexões também expressam a factível influência que as concepções religiosas projetam sobre as pautas de comportamento político, tanto nos processos decisórios de voto, quanto nas condições através das quais se exerce a cidadania e a democracia no país.

O sistema cultural brasileiro contém grandes doses dos esquemas cognitivos típicos do pensamento mágico. Ao isolar esses elementos verificando os sistemas de crença próprios das religiões populares tornam-se claras as correlações entre as categorias de pensamento amplamente disseminadas na sociedade brasileira e as lógicas de uma práxis política. As acepções ora individualistas ora holistas, que decorrem de formulações pós ou pré-éticas, encontradas nessas práticas, e cujas insólitas combinações revelam os "sujeitos descentrados" que emergem em suas pertenças, sinalizam algumas modalidades de conduta relacionadas com comportamentos políticos clientelísticos e personalistas. Tais condutas geram dúvidas sobre a legitimidade da democracia no país e sobre as possibilidades de consolidação da cidadania, ao menos em seus sentidos concebidos como universais. Entretanto, se essas realidades são complexas e danosas para aqueles que as vivem, considera-se que as mesmas não devam ser refletidas sob uma episteme moderna que apenas enuncie as diferenças em relação a outras matrizes possíveis. Tal perspectiva não amplia considerações posteriores aos diagnósticos realizados, e a compreensão de cada sistema em suas próprias conexões e contradições parece oferecer instrumentos reflexivos mais fecundos para descortinar as lógicas de seu funcionamento. A questão não consiste em perceber que certas realidades sociais são "incompletas", mas em evidenciar de que modo as particularidades dessas realidades se conjugam em seus próprios termos. O que parece relevante para 
o caso das relações entre religião e política no Brasil, especialmente na perspectiva dos atores religiosos, é que estes dois universos não se encontram totalmente apartados, suas aproximações consistindo numa espécie de recurso através do qual as contradições da vida social podem ser melhor percebidas e simbolicamente reorganizadas. Avaliar os problemas da práxis política brasileira significa verificar que o ideal de igualitarismo no país nunca foi deveras igualitário, e que é essa contradição que está em jogo quando favores e personalismos se reproduzem em meio e em conjunto com perspectivas liberais. $\mathrm{O}$ mesmo se diz da magia, que não exclui a lógica racional, capitalista e secular, mas opera como complemento aos sentidos cognitivos mais amplos preteridos por aquela perspectiva. No Brasil, por mais contraditório que pareça, favores particulares e liberalismo convivem sem se excluir, magia e racionalidade estão acopladas, e nesses termos, trata-se de um contexto em que as matrizes cognitivas que estruturam o sistema cultural não são nem totalmente mágicas nem secularizadas. Elas residem na cavidade existente entre a magia e o pensamento secular.

\section{REFERÊNCIAS}

ALMOND, Gabriel; VERBA, Sidney. The civic culture: political attitudes and democracy in five nations. Princeton: Princeton University Press, 1989.

ANJOS, José Carlos dos. No território da linha cruzada: a cosmopolítica afro-brasileira. Porto Alegre: Ed. da UFRGS, Fundação Cultural PALMARES, 2006.

BASTIDE, Roger. As religiões africanas no Brasil. Paris: Press Universitaires de France, 1960.

BERGER, Peter. Um rumor de anjos. Rio de Janeiro: Vozes, 1973.

BOHN, Simone. Evangélicos no Brasil: perfil socioeconômico, afinidades ideológicas e determinantes do comportamento eleitoral. Opinião Pública, Campinas, v. 10, n. 2, p. 288-338, 2004.

BRANDÃO, Carlos Rodrigues. Os deuses do povo: um estudo sobre a religião popular. São Paulo: Brasiliense, 1986. 
BRUMANA, Fernando G.; MARTÍNEZ, Elda G. Marginália sagrada. São Paulo: Ed. da Unicamp, 1991.

BURITY, Joanildo. Cultura, identidade e inclusão social: o lugar da religião para seus atores e interlocutores. Debates do NER, Porto Alegre, ano 9, n. 14, p. 11-52, 2008.

BURITY, Joanildo. Religião e política na fronteira: desinstitucionalização e deslocamento numa relação historicamente polêmica. Revista de Estudos da Religião: REVER, São Paulo, n. 4, p. 27-45. 2001.

CAMARGO, Cândido Procópio Ferreira de; SOUZA, Beatriz Muniz de; PIERUCCI, Antonio Flávio. Comunidades eclesiais de base. In: SINGER, Paul; BRANT, Vinícius Caldeira (Org.). São Paulo: o povo em movimento. Petrópolis: Vozes, 1983.

CAMPOS, Leonildo Silveira. O marketing e as estratégias de comunicação da Igreja Universal do Reino de Deus. Estudos de Religião, São Bernardo do Campo, v. 15, p. 2138, 1999.

CAPONE, Stefania. A busca da África no candomblé: tradição e poder no Brasil. Rio de Janeiro: Contra Capa, Pallas, 2004.

CHAMPION, Françoise. Religiosidade flutuante, ecletismos e sincretismos. In:

DELUMEAU, Jean (Org.). As grandes religiões do mundo. Lisboa: Presença, 1997. p. 705733

CORDOVIL, Daniela. A atuação política de afro-religiosos em Belém, Pará: da guerra mágica ao Fórum Social Mundial. Observatório da Religião, Belém, v. 1, n. 1, p. 14-28, 2014.

CORRÊA, Norton. Sob o signo da ameaça: conflito, poder e feitiço nas religiões afrobrasileiras. 1998. Tese (Doutorado em Antropologia) - Pontifícia Universidade Católica, São Paulo, 1998.

DaMATTA, Roberto. Conta de mentiroso: sete ensaios de antropologia brasileira. Rio de Janeiro: Rocco, 1993.

DE BEM, Daniel; LEISTNER, Rodrigo. Caminhos trancados (?): conflitos e projetos políticos afro-religiosos e o processo eleitoral no Rio Grande do Sul. Debates do NER, Porto Alegre, ano 11, n. 18, p. 129-148, jul./dez. 2010.

DURKHEIM, Émile. Las formas elementales de la vida religiosa. Madrid: Alianza, 1993.

EVANS-PRITCHARD, E. E. Bruxaria, oráculos e magia entre os azande. Rio de Janeiro: J. Zahar, 2005. 
FERNANDES, Rubem Cesar. Religiões populares: uma visão parcial da literatura recente. BIB: Revista Brasileira de Informação Bibliográfica em Ciências Sociais. Rio de Janeiro, n. 18, p. 3-26, 1984.

FOLLMANN, José Ivo. Por onde caminham as religiões e religiosidades, hoje: notas para uma reflexão sobre a "secularização encantada". In: WACHHOLZ, Wilhelm (Org.). O luteranismo no contexto religioso brasileiro. São Leopoldo: Sinodal, 2007. p. 9-26.

FRAZER, James. La rama dorada. México: Fondo de Cultura Económica, 1956.

FRY, Peter; HOWE, Gary. Duas respostas à aflição: umbanda e pentecostalismo. Debate e Crítica, São Paulo, n. 6, p. 75-94, 1975.

GOLDMAN, Márcio. A construção ritual da pessoa: a possessão no candomblé. Religião e Sociedade, Rio de Janeiro, ano 5, n. 5, p. 22-55, 1985.

GOMES, Edlaine; NATIVIDADE, Marcelo; MENEZES, Rachel. Proposições de leis e valores religiosos: controvérsias no espaço público. In: DUARTE, Luiz Fernando Dias et al. (Org.). Valores religiosos e legislação no Brasil: a tramitação de projetos de lei sobre temas morais controversos. Rio de Janeiro: Garamond, 2009. p. 15-44.

HERVIEU-LÉGER, Daniele. Le pèlerin et le convert. La religion em mouvement. Paris: Flammarion, 1999.

LEISTNER, Rodrigo. Identidades afro-religiosas no Sul do Brasil: novos formatos associativos e modalidades alternativas de atuação política no contexto das religiões afro-gaúchas. Revista Brasileira de História das Religiões, Maringá, v. 4, p. 103 134, 2011.

LÉVY-BRUHL, Lucien. A mentalidade primitiva. São Paulo: Paulus, 2008.

LODY, Raul. Candomblé: religião e resistência cultural. São Paulo: Ática, 1987.

MACHADO, Maria das Dores Campos. Religião, cultura e política. Religião E Sociedade, Rio de Janeiro, v. 32, p. 29-56, 2012.

MACHADO, Maria das Dores Campos. Religião e política no Brasil contemporâneo: uma análise dos pentecostais e carismáticos católicos. Religião E Sociedade, Rio de Janeiro, v. 35, p. 45-72, 2015.

MAGGIE, Yvonne. Medo do feitiço: relações entre magia e poder no Brasil. Rio de Janeiro: Arquivo Nacional, 1992.

MAINWARING, Scott P. Igreja católica e política no Brasil. São Paulo: Brasiliense, 2004.

MAINWARING, Scott P. Sistemas partidários em novas democracias: o caso do Brasil. Porto Alegre: Mercado Aberto, 2001. 
MALUF, Sônia. Os filhos de aquário no país dos terreiros: novas vivências espirituais no sul do Brasil. Ciências Sociais e Religião, Porto Alegre, ano 5, n. 5, p. 153-171, 2003.

MARIANO, Ricardo. Expansão pentecostal no Brasil: o caso da Igreja Universal. Estudos Avançados, São Paulo, v. 18, n. 52, p. 121-138, 2004.

MARIZ, Cecília Loreto. A religião e o enfrentamento da pobreza no Brasil. Revista Crítica de Ciências Sociais, n. 33, p. 11-24, 1991.

MARTÍN, Eloísa. From Popular Religion to Practices of Sacralization: approaches for a conceptual discussion. Social Compass, n56, vol.2, 2009, pp. 273-285.

MENDONÇA, Antonio Gouvêa; FILHO, Prócoro Velasques. Introdução ao Protestantismo no Brasil. São Paulo: Edições Loyola, 1990.

MONTERO, Paula. Religiões e dilemas da sociedade brasileira. In: MICELI, Sérgio. (org.) O que ler na Ciência Social brasileira (1970-1995). v. 1: Antropologia. São Paulo: Sumaré/ Anpocs; Brasília: Capes, 1999, p. 327-367.

MONTERO, Paula. Magia, Racionalidade e Sujeitos Políticos. Revista Brasileira de Ciências Sociais, n 26, ano 9, São Paulo, outubro de 1994.

MORIN, Edgar. O Método III. O conhecimento do conhecimento / 1. Porto Alegre: Sulina, 1996.

NEGRÃO, Lísias. Entre a Cruz e a Encruzilhada: Formação do Campo Umbandista em São Paulo. São Paulo: Editora da Universidade de São Paulo, 1996.

NEGRÃO, Lísias; CONCONE, Maria Helena. Umbanda: da Repressão à Cooptação - O envolvimento político-partidário da umbanda paulista nas eleições de 1982. In: ISER. (Org.). Umbanda e Política. Rio de Janeiro: Marco Zero/ISER, 1985.

ORO, Ari Pedro. As Religiões Afro-Brasileiras do Rio Grande do Sul. Debates do NER, Porto Alegre, ano 9, no..13, Janeiro/Junho de 2008, pp. 9-23.

ORO, Ari Pedro. Religião e Política na América Latina: uma análise da legislação dos países. Horizontes Antropológicos, Porto Alegre, ano 13, nº. 27, 2007, pp. 281-310.

ORO, Ari Pedro. O neopentecostalismo macumbeiro. Revista USP, São Paulo, nº.68, 2006, pp. 319-332.

ORO, Ari Pedro. A Política da Igreja Universal e seus Reflexos nos Campos Religioso e Político Brasileiros. Revista Brasileira de Ciências Sociais. vol. 18, no‥53, Outubro, 2003, pp. 54-69.

ORO, Ari Pedro. Religião e política nas eleições 2000 em Porto Alegre. Debates do NER, Porto Alegre, ano 2, no.3, Set, 2001, pp. 09-70. 
ORO, Ari Pedro. Religião e Política nos Países do Cone-Sul. In: ORO, Ari Pedro.; STEIL, Carlos Alberto. (Orgs.). Globalização e Religião. Petrópolis: Vozes, 1997.

ORTIZ, Renato. A morte branca do feiticeiro negro: umbanda. Petrópolis: Vozes, 1978.

PELS, Peter. Introduction: magic and modernity. In: MEYER, Birgit; PELS, Peter (Orgs.). Magic and Modernity: interfaces of revelation and concealment. Stanford: Stanford University Press, 2003.

PIERUCCI, Antonio Flávio. Apêndice: as religiões no Brasil. In: HELLERN, Victor. (Org.). O Livro das Religiões. São Paulo: Cia. das Letras, 2000.

PIERUCCI, Antonio Flávio; PRANDI, Reginaldo. A Realidade Social das Religiões no Brasil: religião, sociedade e política. São Paulo: Huitec, 1996

PRANDI, Reginaldo. As religiões afro-brasileiras e seus seguidores. Civitas, Porto Alegre, v. 3, no. 1, Jun., 2003, pp. 15-33.

PRANDI, Reginaldo.“Hipertrofia ritual das religiões afro-brasileiras”. Novos Estudos Cebrap, São Paulo, no. 56, 2000, pp. 77-88.

PRANDI, Reginaldo. Perto da Magia, Longe da Política. In: PIERUCCI, Antonio Flávio.; PRANDI, Reginaldo. (Orgs.). A Realidade Social das Religiões no Brasil: religião, sociedade e política. São Paulo: Huitec, 1996.

PRANDI, Reginaldo. Os Candomblés de São Paulo. São Paulo: Hucitec - Edusp, 1991.

ROLIM, Francisco Cartaxo. Pentecostais no Brasil: uma interpretação sócio-religiosa. Petrópolis: Vozes, 1985.

SILVA, Vagner Gonçalves da. Concepções religiosas afro-brasileiras e neopentecostais: uma análise simbólica. Revista USP, São Paulo, n.․ 67, 2005, pp. 150-175.

SLENES, Robert. Lares Negros, Olhares Brancos: histórias da família escrava no Século XIX. Revista Brasileira de História - AMPUH: Escravidão. São Paulo, V. 8, n 16, 1988, pp. 189-203.

STEIL, Carlos Alberto. Pluralismo, Modernidade e Transformações do Campo Religioso. Ciências Sociais e Religião, Porto Alegre, ano 3, no‥ 3, 2001, pp. 115-129.

VELHO, Gilberto. Projeto e Metamorfose: antropologia das sociedades complexas. Rio de Janeiro: Jorge Zahar Editor, 1994.

WEBER, Max. Economia e Sociedade: fundamentos da sociologia compreensiva. Brasília, Editora da Universidade de Brasília, 1994. 